\title{
Human fetal bone cells associated with ceramic reinforced PLA scaffolds for tissue engineering
}

\author{
Marc-Olivier Montjovent ${ }^{\mathrm{a}}$, Silke Mark ${ }^{\mathrm{b}}$, Laurence Mathieu ${ }^{\mathrm{c}}$, Corinne Scaletta ${ }^{\mathrm{d}}$, \\ Arnaud Scherberich ${ }^{\mathrm{e}}$, Claire Delabarde ${ }^{\mathrm{a}}$, Pierre-Yves Zambelli ${ }^{\mathrm{f}}$, Pierre-Etienne Bourban ${ }^{\mathrm{c}}$, \\ Lee Ann Applegate ${ }^{\mathrm{d}}$, Dominique P. Pioletti ${ }^{\mathrm{a}, *}$

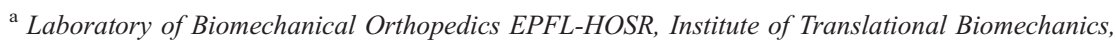 \\ Ecole Polytechnique Fédérale de Lausanne, CH-1015 Lausanne, Switzerland \\ ${ }^{\mathrm{b}}$ Ludwig Institute for Cancer Research, Lausanne Branch, Epalinges, Switzerland \\ ${ }^{\mathrm{c}}$ Laboratory of Polymer and Composite Technology, Ecole Polytechnique Fédérale de Lausanne, CH-1015 Lausanne, Switzerland \\ d Orthopedic Cell Therapy Unit, PAV-03, Centre Hospitalier Universitaire Vaudois and University of Lausanne, CH-1005 Lausanne, Switzerland \\ ${ }^{\mathrm{e}}$ Tissue Engineering, Department of Research, Basel University Hospital, CH-4031 Basel, Switzerland \\ ${ }_{\mathrm{f}}^{\mathrm{f}}$ Hopital Orthopédique de la Suisse Romande, CH-1005 Lausanne, Switzerland
}

Received 25 July 2007; revised 21 September 2007; accepted 22 October 2007

Available online 7 November 2007

\begin{abstract}
Fetal bone cells were shown to have an interesting potential for therapeutic use in bone tissue engineering due to their rapid growth rate and their ability to differentiate into mature osteoblasts in vitro. We describe hereafter their capability to promote bone repair in vivo when combined with porous scaffolds based on poly(L-lactic acid) (PLA) obtained by supercritical gas foaming and reinforced with 5 wt.\% $\beta$-tricalcium phosphate (TCP).

Bone regeneration was assessed by radiography and histology after implantation of PLA/TCP scaffolds alone, seeded with primary fetal bone cells, or coated with demineralized bone matrix. Craniotomy critical size defects and drill defects in the femoral condyle in rats were employed. In the cranial defects, polymer degradation and cortical bone regeneration were studied up to 12 months postoperatively. Complete bone ingrowth was observed after implantation of PLA/TCP constructs seeded with human fetal bone cells. Further tests were conducted in the trabecular neighborhood of femoral condyles, where scaffolds seeded with fetal bone cells also promoted bone repair.

We present here a promising approach for bone tissue engineering using human primary fetal bone cells in combination with porous PLA/TCP structures. Fetal bone cells could be selected regarding osteogenic and immune-related properties, along with their rapid growth, ease of cell banking and associated safety.
\end{abstract}

(C) 2007 Elsevier Inc. All rights reserved.

Keywords: Human fetal bone cells; Bone regeneration; Bone tissue engineering; Scaffold; Polylactic acid

\section{Introduction}

Fetal bone cells were shown to proliferate, differentiate and finally to mineralize their extra cellular matrix in vitro [1]. For these reasons, we decided to test their association with porous scaffolds for bone repair in vivo.

\footnotetext{
* Corresponding author. EPFL STI IBME LBO-EPFLHOSR, AI 1137 (Bâtiment AI), Station 15, CH-1015 Lausanne, Switzerland. Fax: +41 21693 8660 .

E-mail address: dominique.pioletti@epfl.ch (D.P. Pioletti).
}

Ceramic reinforced poly(L-lactic acid) (PLA) structures obtained by melt-extrusion followed by supercritical gas foaming offer suitable conditions for primary human osteoblasts to achieve a full differentiation process in vitro [2]. Moreover, open frames are designed with defined parameters to improve the osteoconductivity, such as porosity, pore size, and connectivity, as well as enhanced mechanical properties [3]. Furthermore, this technique allows producing biocompatible samples without the use of potentially toxic organic solvents [4,5]. These structures were recently tested in vivo for host tissue induced reactions as well as for their osteoconductive properties [6]. 
Critical size defect models (CSD) are often used to study orthopaedic materials [7]. A CSD is defined to be the smallest in situ bone wound that would not heal spontaneously by bone formation during the lifespan of the animal [8]. Thus, the CSD created on the bony vault of the cranium (calvaria) represents a severe test for bone graft substitutes. CSDs in the calvaria have been established for different mammalian species [9-14]. Modelling on parietal bone has been applied on rats from different strains and at various ages [10,15-18]. Three months old Sprague-Dawley rats did not spontaneously fill $8 \mathrm{~mm}$ diameter lacunae 18 weeks post-surgery [6].

Several animal models are described to test implants in cancellous bone [19-21] and the femoral condyle is often used for this purpose $[22,23]$. Due to its vascularization and the presence of precursor cells, this location is of particular interest to assess in parallel biodegradation and bone repair processes [24].

For cell-based approaches in bone tissue engineering, bone marrow preparations [25], mesenchymal stem cells (MSCs) [26,27], and osteoprogenitor cells [28] have been used. Recently, fetal bone cells were characterized in vitro to investigate their potential use for tissue engineering [1]. They were shown to be able to proliferate and differentiate into mature osteoblasts in vitro when seeded on PLA/TCP scaffolds [2].

In the present study, we describe the combination of fetal bone cells with PLA/5 wt.\% $\beta$-tricalcium phosphate (PLA/TCP) implants for cortical and trabecular bone repair. Fetal bone cells were used in their proliferating phase without induction of differentiation to evaluate their osteogenic potential in vivo. In rat cranial defects, cortical bone regeneration was assessed with PLA/TCP implants with and without fetal bone cells as well as with $\beta$-tricalcium phosphate matrices (designated as $\beta$-TCP Mathys hereafter), corresponding to the composition and structure of chronOS ${ }^{\mathrm{TM}}$ scaffolds already used in clinical applications (Mathys, Bettlach, Switzerland). In parallel, both scaffolds were coated with demineralized bone matrix (DBM) to improve their osteoinductivity and to compare them for cortical bone regeneration with scaffolds seeded with cells. To further evaluate the osteoconduction of PLA/TCP implants and the osteogenesis induced by fetal bone cells, PLA/ceramic structures with or without cells were implanted in the metaphyseal trabecular network of rat femoral condyles.

We demonstrate here for the first time, the high potential of human fetal bone cells associated with PLA/ceramic composite structures processed by supercritical gas foaming for their use in cortical and trabecular bone repair.

\section{Materials and methods}

\section{Cell sources}

Human fetal bone cells were obtained from our cell bank comprising eight donors at the end of April 2007. Biopsies were obtained in accordance with the Ethics Committee of the University Hospital in Lausanne (Ethical Protocol 51/01). In this study, bone cells from a fetus of 15 weeks gestational age were used following voluntary interruption of pregnancy. Primary osteoblast cultures were established by rinsing the tissue first with PBS (containing penicillin and streptomycin for washing only). Afterwards, bone samples were mechanically dissociated with a scalpel blade and transferred to $10 \mathrm{~cm}$ culture grade plates where cell outgrowth was seen within 2 to 5 days under normal culture conditions:
DMEM (Invitrogen, Carlsbad, CA), 10\% FCS (Sigma-Aldrich, St Louis, MO), $2 \mathrm{mM}$ L-Glutamin (Invitrogen, Carlsbad, CA).

\section{Cell culture}

Fetal bone cells were maintained in culture by passaging once a week and culturing at $37{ }^{\circ} \mathrm{C}$ in a humidified, $5 \% \mathrm{CO}_{2}$ atmosphere in DMEM,10\% FCS, $2 \mathrm{mM}$ L-Glutamine. Culture media were changed twice a week.

\section{Scaffold generation}

The processing of foams, as well as analyses of scaffold morphology and properties, were carried out and described in detail elsewhere [3]. Poly(L-lactic acid) pellets (PLA; Boehringher Ingelheim, Germany), and $\beta$-tricalcium phosphate ( $\beta$ TCP) ceramic powder (Fluka, Buchs SG, Switzerland) (5 wt.\%) were mixed, and further melt-extruded using a micro-compounder (Micro 5 Compounder; DSM, The Netherlands) [29]. Foaming was then carried out with supercritical $\mathrm{CO}_{2}$ (pure $>99.995 \%$; SL gas, Switzerland), in a custom made high-pressure chamber (Autoclave France, France). Once $\mathrm{CO}_{2}$ was dissolved in PLA, foaming was achieved by sudden gas release, which induces bubble nucleation and their growth. Simultaneous cooling fixes the porous structure. PLA $/ 5 \mathrm{wt} . \% \beta$-TCP (PLA/TCP) scaffolds tested in vivo in this study were processed using the following parameters: saturating pressure of $226 \mathrm{bar}$; depressurization rate of $4.5 \mathrm{bar} / \mathrm{s}$; cooling rate of $4.4{ }^{\circ} \mathrm{C} / \mathrm{s}$. In parallel, $\beta$-TCP scaffolds ( $\beta$-TCP Mathys), corresponding to

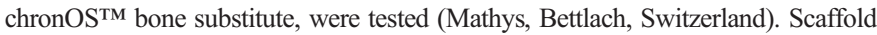
morphology was evaluated by micro-computed tomography, and by scanning electron microscopy [30]. Ceramic distribution was assessed and described elsewhere $[29,30]$. Implanted volumes were machined into cylinders ( $2 \mathrm{~mm}$ high, $8 \mathrm{~mm}$ diameter for the calvaria and $3 \mathrm{~mm}$ high, $3 \mathrm{~mm}$ diameter for the condyle model).

\section{Scaffold coating with demineralized bone matrix}

Scaffold coating with DBM (National Tissue Bank, University of Pretoria, Pretoria, Republic of South Africa) was achieved by mixing demineralized bone particles with a fibrin sealer (Tissucol ${ }^{\circledR}$ Kit, Baxter, Vienna, Austria). Briefly, the lyophilized fibrinogen concentrate was dissolved in aprotinin solution $(3000 \mathrm{KIU} / \mathrm{ml})$ as described by the manufacturer. Thrombin was dissolved in calcium chloride solution $(40 \mu \mathrm{mol} / \mathrm{ml})$ to a concentration of $4 \mathrm{IU} / \mathrm{ml}$. The fibrin gel was prepared by mixing both components at equal volumes. DBM fragments (30 mg/scaffold) were rapidly glued on scaffold surfaces while the sealant was still liquid (within approximately $1 \mathrm{~min}$ )

\section{Microtomographic imaging}

The samples were scanned using a microtomographic imaging system ( $\mu \mathrm{CT} 40$; Scanco Medical, Bassersdorf, Switzerland) equipped with a $5 \mu \mathrm{m}$ focal spot X-ray tube as a source. The X-ray tube was operated at $70 \mathrm{kVp}$ and $114 \mu \mathrm{A}$. The integration time was set to $300 \mathrm{~ms}$. CT images were reconstructed in $1024 \times 1024$ pixel matrices from 500 projections using a standard convolution-backprojection procedure. Images were stored in 3D arrays with an isotropic voxel size of $12 \mu \mathrm{m}$.

\section{Scanning electron microscopy}

Samples were rinsed with PBS (Invitrogen, Carlsbad, CA) prior to fixation with primary glutaraldehyde fixative: $0.1 \mathrm{M}$ sodium cacodylate (Polysciences Inc, Warrington, PA), 5\% glutaraldehyde (Polysciences Inc, Warrington, PA), $0.1 \mathrm{M}$ sucrose (Axon Lab AG, Baden-Dätwill, Switzerland), $\mathrm{pH} 7.4$ for $45 \mathrm{~min}$ at $4{ }^{\circ} \mathrm{C}$. The fixative was then replaced by a buffered sucrose vehicle: $0.1 \mathrm{M}$ sodium cacodylate, $0.1 \mathrm{M}$ sucrose, $\mathrm{pH} 7.4$, for $30 \mathrm{~min}$ at $4{ }^{\circ} \mathrm{C}$. After this step, bones were placed in osmium fixative: $0.1 \mathrm{M}$ sodium cacodylate, $0.1 \mathrm{M}$ sucrose, $1 \%$ osmium tetroxyde (Polysciences Inc, Warrington, PA), $\mathrm{pH} 7.4$, for $60 \mathrm{~min}$ at $4{ }^{\circ} \mathrm{C}$. Samples were washed twice at room temperature with demineralized water before dehydration and air-drying from a solution of hexamethyldisilazane (Polysciences Inc, Warrington, PA). The sample surfaces were gold-coated during 2 min under $1 \mathrm{kV}$ and observed using a scanning electron microscope Philips XL30 (FEI, Hillsboro, OR) at a voltage of $5 \mathrm{kV}$. 


\section{Cell seeding}

Scaffolds were placed in 24-well plates and washed with complete culture medium. Cells were seeded by direct pipetting at a density of $2 \times 10^{6}$ cells/ scaffold. This density was selected, as a good cell distribution and an exponentional cell growth reaching the plateau after 10 days were observed in vitro. Moreover, the cell density retained was consistent with the one used by others for similar cell phenotype [31,32]. After $2 \mathrm{~h}$, additional culture medium was distributed around the scaffolds. They were incubated for $24 \mathrm{~h}$ at $37^{\circ} \mathrm{C}$ in a humidified, $5 \% \mathrm{CO}_{2}$ atmosphere.

\section{Animals and housing}

All animal experiments were performed with the approval of the Veterinary Authority from the Canton of Vaud (authorizations No. 1777 and 1878). SpragueDawley albino or Wistar rats (females, 84-92 days old, 275-300 g) were purchased from Iffa Credo (Charles River Laboratories, L'Arbresle Cedex, France) for the craniotomy and the femoral condyle models, respectively. Animals were grouped by 3 on wood-based litters in PET cages $(405 \times 255 \times 197 \mathrm{~mm})$ equipped with Reemay filter covers (no. E4FVCOU910, Charles River Laboratories, L'Arbresle Cedex, France). Strictly controlled housing conditions were used: temperature: $22 \pm 2{ }^{\circ} \mathrm{C}$, relative humidity: $55 \pm 10 \%$, light/dark hours schedule:12/12. They were fed a balanced solid diet (Mouse/Rat - complete feed extrudate 3436, Provimi Kibla AG, Switzerland). Food and water were provided ad libitum during the experiment.

\section{Rat surgery}

Table 1 summarizes all conditions tested for the cranial and the femoral models, respectively.

Rats were anesthetized with isoflurane $2-3.5 \%$ in oxygen. For the calvarial surgery, once sedated, the animals were shaved and the cranial surface sterily prepared with alcohol. The animals were placed on a heating pad to maintain body temperature during the procedure. A midline incision (approximatively $3 \mathrm{~cm}$ long) was made from the nasal bone to the crest using a surgical blade. The soft tissue and the periosteum were elevated. The craniotomy defect $(8 \mathrm{~mm})$ was created with a trephine drill (no. 207421, Provet SA, Lyssach, Switzerland) under constant saline irrigation and the underlying dura was preserved. The resulting defect was grafted with scaffolds made either of PLA/TCP, PLA/TCP/

Table 1

Experimental design for the cranial and femoral models

\begin{tabular}{|c|c|c|c|}
\hline \multicolumn{4}{|l|}{ CSD craniotomy } \\
\hline $\begin{array}{l}\text { Implants/ } \\
\text { surgery }\end{array}$ & Comments & Time points & Group size \\
\hline Sham surgery & No implantation & $\begin{array}{l}12 \text { days, } 6 \text { months, } \\
12 \text { months }\end{array}$ & $n=6$ \\
\hline PLA/TCP & $\mathrm{PLA}+5$ wt. $\% \beta-\mathrm{TCP}$ & $\begin{array}{l}12 \text { days, } 6 \text { months, } \\
12 \text { months }\end{array}$ & $n=6$ \\
\hline PLA/TCP/DBM & $\begin{array}{l}30 \mathrm{mg} \text { DBM/scaffold, } \\
\text { glued with Tissucol }{ }^{\circledR} \text { Kit }\end{array}$ & $\begin{array}{l}12 \text { days, } 6 \text { months, } \\
12 \text { months }\end{array}$ & $n=6$ \\
\hline $\begin{array}{l}\mathrm{PLA} / \mathrm{TCP} / \mathrm{fetal} \\
\text { bone cells }\end{array}$ & $\begin{array}{l}2 \text { mio cells/scaffold, } \\
\text { donor } 15 \text { weeks } \\
\text { gestational age }\end{array}$ & $\begin{array}{l}12 \text { days, } 6 \text { months, } \\
12 \text { months }\end{array}$ & $n=6$ \\
\hline$\beta$-TCP Mathys & $\begin{array}{l}\beta \text {-TCP scaffolds } \\
\text { corresponding to } \\
\text { chronOS }{ }^{\text {TM }} \text { matrice }\end{array}$ & $\begin{array}{l}12 \text { days, } 6 \text { months, } \\
12 \text { months }\end{array}$ & $n=6$ \\
\hline $\begin{array}{l}\text { ß-TCP Mathys/ } \\
\text { DBM }\end{array}$ & $\begin{array}{l}30 \mathrm{mg} \text { DBM/scaffold, } \\
\text { glued with Tissucol }{ }^{\circledR} \text { Kit }\end{array}$ & $\begin{array}{l}12 \text { days, } 6 \text { months, } \\
12 \text { months }\end{array}$ & $n=6$ \\
\hline \multicolumn{4}{|l|}{ Femoral condyle } \\
\hline Implants & Comments & Time points & Group size \\
\hline PLA/TCP & PLA +5 wt. $\% \beta-\mathrm{TCP}$ & 2 months & $n=12$ \\
\hline $\begin{array}{l}\mathrm{PLA} / \mathrm{TCP} / \text { fetal } \\
\text { bone cells }\end{array}$ & $\begin{array}{l}2 \text { mio cells/scaffold, donor } \\
15 \text { weeks gestational age }\end{array}$ & 2 months & $n=12$ \\
\hline
\end{tabular}

DBM, PLA/TCP with fetal bone cells, $\beta$-TCP Mathys, or $\beta$-TCP Mathys/DBM. The skin was closed with stainless steel surgical clips. Postoperative analgesia was provided by subcutaneous injection of Butorphanol Morphasol ${ }^{\circledR} 0.03 \mathrm{ml}$ (Dr E. Gräub AG, Bern, Switzerland). At the determined time points, animals were sacrificed by $\mathrm{CO}_{2}$ asphyxiation. Craniotomy sites with $5 \mathrm{~mm}$ neighboring bone were collected from the skull and placed in $4 \%$ buffered formaldehyde. Aseptic surgical technique was used throughout the procedure, and each condition was tested in six replicates. For the cranial model used in this study, 108 animals were randomly assigned to the different groups and for the three time points, including rats undergoing sham surgery $(n=6)$.

Implants made of PLA/TCP with or without fetal bone cells were further tested in a drill hole model in the distal femoral condyles of rats. For this, twelve female rats were used. Under general isoflurane anesthesia, both femoral distal condyles in each rat were exposed. The diameter and depth of the hole created transversally in the bone were both $3 \mathrm{~mm}$. After washing the cavity with physiological saline to remove debris, the defects were filled with implants (PLA/ TCP and PLA/TCP with fetal bone cells, $n=12$ for each group). The fascia and skin were then closed using suture material or stainless steel surgical clips, respectively. Postoperative analgesia was provided by subcutaneous injection of Butorphanol Morphasol ${ }^{\circledR} 0.03 \mathrm{ml}$. At 2 months following surgery, animals were sacrificed by $\mathrm{CO}_{2}$ asphyxiation, and femurs were processed for histology as described hereafter.

\section{Histological evaluation}

After fixation in $4 \%$ buffered formaldehyde, samples were dehydrated in a series of increasing concentrations of ethanol (50-100\%), defatted in xylene and infiltrated at $4{ }^{\circ} \mathrm{C}$ with methylmethacrylate (Fluka Chemie $\mathrm{GmbH}$, Buchs, Switzerland), dibuthylphtalate (Merck Schuchardt, Hohenbrunn, Germany) and Perkadox 16 (Dr. Grogg Chemie AG, Stettlen, Switzerland). Specimens were embedded at room temperature in a fresh solution of acrylic resin. To visualize bone formation, slides of $300 \mu \mathrm{m}$ thickness were sectioned with a diamond sawrotating microtome (Leica ${ }^{\circledR}$ Sp1600, Leica Instruments GmbH, Nussloch, Germany). Cranial sections were obtained frontally, at the level of the maximum diameter of the craniotomy, and femoral sections were obtained sagittally. Sections were radiographed, ground down to $30-40 \mu \mathrm{m}$ and polished as described elsewhere [33]. They were stained with toluidine blue, which in its orthochromatic phase, stains bone components in various shades of blue, enabling the distinction between the non-mineralized osteoid and the mineralized bone matrix. It represents the standard technology in our laboratory for the histological staining of non-decalcified ground sections where after chemical surface etching only toluidine blue can be used. Goldner's trichrome is not usable for this purpose and does also not reveal more information.

For the calvaria model, ground sections were photographed at a low magnification $(\times 5.8)$ with a microscope (Leica M420 ${ }^{\circledR}$, Leica microsystems, Switzerland) equipped with a digital camera (Leica DC200 ${ }^{\circledR}$ ). The histological analysis was performed with respect to scaffold degradation and newly formed bone. Regarding the formation of new bone, a semi-quantitative scoring system was used. Briefly, a healing score was assigned to each implant as follows: A) bony recovery along the dura: 0 for no repair; 1 for $0-25 \% ; 2$ for $26-50 \% ; 3$ for more than $50 \%$ of repair, B) porous ossification inside the scaffold structures: 0 for no ossification; 1 for ossification observed on up to $25 \%$ of the total area (scaffold plus pores); 2 for ossification observed on up to $50 \%$ of the total area, and 3 for ossification observed on more than $50 \%$ of the total area. In order to obtain more representative results, two histological sections of each animal were analyzed and subsequently, the mean value of each parameter was calculated for every animal The obtained healing scores were further classified into four categories, which were: no $(0)$, weak $(\leq 1)$, moderate $(\leq 2)$, and strong $(\leq 3)$ healing.

For the condyle model, and for each implant, one representative section was analyzed. Thick sections were photographed at a magnification of $16 \times$ (Leica M420 ${ }^{\circledR}$, Leica microsystems, Switzerland) equipped with a digital camera (Leica DC200 ${ }^{\circledR}$ ). Three software programs were used for image analysis (Leica $\operatorname{IM} 100^{\circledR}$, Leica QWin ${ }^{\circledR}$ and Adobe Photoshop $7^{\circledR}$ ). Only the defect area corresponding to the implant itself was analyzed. New bone was stained manually to ensure accurate detection during the measurement. Absolute values were converted into percentages of the total area using Microsoft Excel ${ }^{\mathbb{}}$. A student $t$-test was applied to assess the effect of fetal bone cells on new bone formation within the PLA/TCP scaffolds. 


\section{Radiography of rat specimen}

The presence of newly formed bone was determined radiographically (Faxitron X-ray systems, Hewlett Packard, Oregon, USA). Skulls were placed with the exocranial surfaces on top of a radiographic film (Kodak Portal Pack for Localization Imaging, Eastman Kodak Company, Rochester, NY). Samples were imaged and processed with an image analysis software (ImageJ, Wayne Rasband, National Institutes of Health, Bethesda, MD). Histograms of each defect area were determined on digitized radiographs, and background values were subtracted. Femurs were radiographed as thick sections of $300 \mu \mathrm{m}$, in order to visualize bone infiltration in implants without surrounding bone.

\section{Statistical analysis}

Animals were randomly assigned to the different groups. All conditions were tested with six replicates for the craniotomy and twelve replicates for the femoral model. Semi-quantitative, histological analysis of bone repair and analysis of X-rays images were performed blinded to the treatment groups. Unless otherwise specified, results are presented as mean values with standard deviation of the mean.

\section{Results}

\section{Scaffold generation and quality control}

Porosity and pore size were verified to be in the expected range of $75-90 \%$ and $200-500 \mu \mathrm{m}$, respectively, for the PLA/TCP scaffold (Fig. 1A) using micro-CT and scanning electron microscopy. The following values were obtained: porosity: $83.4 \pm$ $2.5 \%$; pore diameter: $390 \pm 180 \mu \mathrm{m}$; modulus: $121.0 \pm 12.1 \mathrm{MPa}$
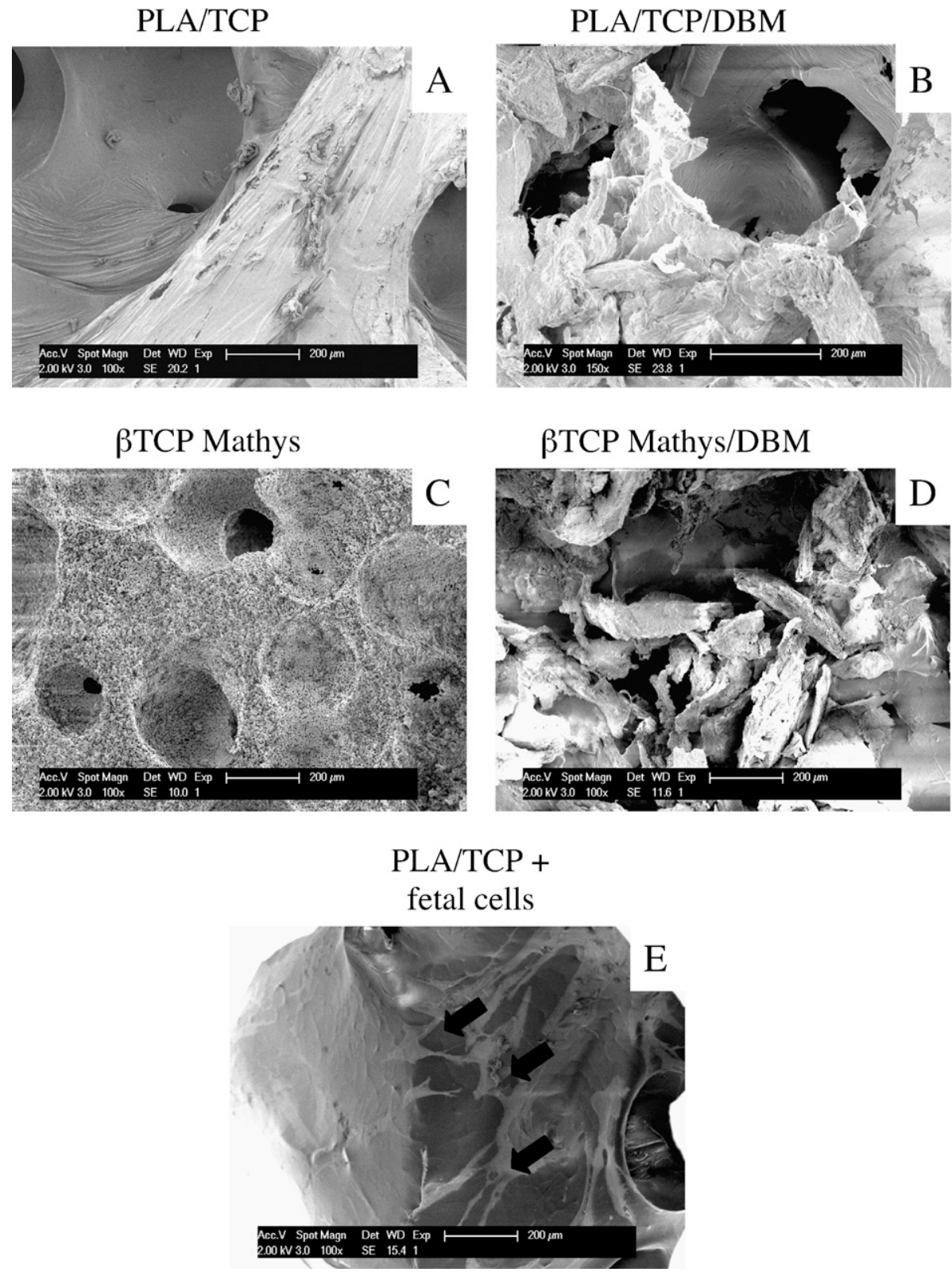

Fig. 1. Scanning electron micrographs of scaffold structures. (A) PLA 5 wt. $\% \beta$-TCP: porosity $83.4 \pm 2.5 \%$, pore diameter: $390 \pm 180 \mu$ m, modulus $121.0 \pm 12.1$ MPa. (B) Same scaffolds made of PLA 5 wt.\% $\beta$-TCP, coated with DBM. (C) $\beta$-TCP Mathys: porosity $75.4 \pm 0.3 \%$, pore diameter: $410 \pm 30 \mu$ m, modulus $2.70 \pm 0.44 \mathrm{GPa}$. (D) Same scaffolds made of $\beta$-TCP, coated with DBM. (E) Fetal bone cells proliferating on PLA 5 wt.\% $\beta$-TCP scaffolds $24 \mathrm{~h}$ after seeding. Black arrows indicate spreading cells. Scale bar: $200 \mu \mathrm{m}$. 
Table 2

Histological semi-quantitative evaluation of bone repair, 12 days, 6 months and 12 months after implantation in skulls

\begin{tabular}{|c|c|c|c|c|c|c|c|c|c|}
\hline \multicolumn{10}{|l|}{ A. Ossification along the dura } \\
\hline \multirow[b]{2}{*}{ Duration of implantation (weeks) } & \multicolumn{3}{|c|}{ PLA/TCP } & \multicolumn{3}{|c|}{ PLA/TCP/DBM } & \multicolumn{3}{|c|}{ PLA/TCP/fetal cells } \\
\hline & $12 / 7$ & 24 & 48 & $12 / 7$ & 24 & 48 & $12 / 7$ & 24 & 48 \\
\hline & 0 & 0.3 & 1.2 & 0 & 0.5 & 2.5 & 0 & 0.8 & 1.3 \\
\hline & $(0-0)$ & $(0-1)$ & $(0-3)$ & $(0-0)$ & $(0-1)$ & $(1-3)$ & $(0-0)$ & $(0-2)$ & $(1-3)$ \\
\hline \multirow[t]{2}{*}{ Bone Repair } & None & Weak & Moderate & None & Weak & Strong & None & Weak & Moderate \\
\hline & \multicolumn{3}{|c|}{$\beta$-TCP Mathys } & \multicolumn{3}{|c|}{$\beta$-TCP Mathys/DBM } & & & \\
\hline \multirow[t]{3}{*}{ Duration of implantation (weeks) } & $12 / 7$ & 24 & 48 & $12 / 7$ & 24 & 48 & & & \\
\hline & 0 & 0.7 & 0 & 0 & 0.8 & 2.7 & & & \\
\hline & $(0-0)$ & $(0-1)$ & $(0-0)$ & $(0-0)$ & $(0-1)$ & $(2-3)$ & & & \\
\hline Bone repair & None & Weak & None & None & Weak & Strong & & & \\
\hline \multicolumn{10}{|l|}{ B. Porous ossification } \\
\hline & \multicolumn{3}{|c|}{ PLA/TCP } & \multicolumn{3}{|c|}{ PLA/TCP/DBM } & \multicolumn{3}{|c|}{ PLA/TCP/fetal cells } \\
\hline \multirow[t]{3}{*}{ Duration of implantation (weeks) } & $12 / 7$ & 24 & 48 & $12 / 7$ & 24 & 48 & $12 / 7$ & 24 & 48 \\
\hline & 0 & 0.2 & 0.3 & 0 & 0 & 0 & 0 & 0.2 & 1.2 \\
\hline & $(0-0)$ & $(0-1)$ & $(0-1)$ & $(0-0)$ & $(0-0)$ & $(0-0)$ & $(0-0)$ & $(0-1)$ & $(0-3)$ \\
\hline \multirow[t]{2}{*}{ Bone ingrowth } & None & Weak & Weak & None & None & None & None & Weak & Moderate \\
\hline & \multicolumn{3}{|c|}{$\beta$-TCP Mathys } & \multicolumn{3}{|c|}{$\beta$-TCP Mathys/DBM } & & & \\
\hline \multirow[t]{3}{*}{ Duration of implantation (weeks) } & $12 / 7$ & 24 & 48 & $12 / 7$ & 24 & 48 & & & \\
\hline & 0 & 1.2 & 2 & 0 & 1 & 1.8 & & & \\
\hline & $(0-0)$ & $(1-2)$ & $(1-3)$ & $(0-0)$ & $(1-1)$ & $(1-3)$ & & & \\
\hline Bone ingrowth & None & Weak & Moderate & None & Weak & Moderate & & & \\
\hline
\end{tabular}

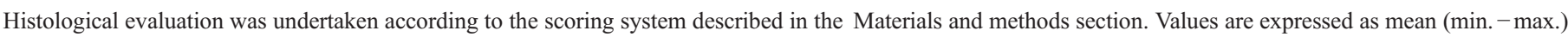
for each group of implants at the corresponding time point.

(expected: value: $150 \mathrm{MPa}$ ). Furthermore, the $\beta$-TCP Mathys scaffolds (Fig. 1C) were examined showing a porosity of $75.4 \pm$ $0.3 \%$, a pore diameter of $410 \pm 30 \mu \mathrm{m}$ and a modulus of $2.70 \pm$ $0.44 \mathrm{GPa}$.

Coating of the scaffolds with DBM was controlled by scanning electron microscopy. Numerous DBM fragments could be detected covering the outer surface of the PLA/TCP/DBM and $\beta$-TCP Mathys/DBM scaffolds (Fig. 1B and D).

Cell adherence and scaffold infiltration was examined by scanning electron microscopy prior to implantation (Fig. 1E) showing proliferating cells all over the surface of the scaffolds.

\section{Histology of cranial samples}

First evidence of PLA/TCP scaffold degradation was observed at 6 months and more advanced degradation at 12 months after surgery. Changes concerning bulk morphology and porosity were noted. Fragmentation was rarely observed. The structures of $\beta$-TCP Mathys were practically unchanged at the 12 months time point which corresponded to the end of the study.

The presence of DBM debris induced symptoms of inflammation in the PLA/TCP/DBM and $\beta$-TCP Mathys/ DBM groups at 12 days after implantation. Swelling was mainly due to local fluid influx and disappeared 3 months after surgery as assessed in a pilot study (data not shown).

Bone healing processes were evaluated semi-quantitatively and results are summarized in Table 2. Repair observed 12 months postoperatively are illustrated by photomicrographs of stained cranial sections in Fig. 2, and no sign of necrosis was noted. Sham operated animals were not able to close the defects with new bone at this time point (Fig. 2F).

PLA/TCP: new bone formation started mainly from the edge of the defects and along the dura showing the osteoconductive property of these scaffolds (Table 2A, Fig. 2A). Almost no ossification of the porous scaffold structure was observed (Table 2B). The healing process was delayed when a layer of fibrous tissue was present between the implants and the dura.

PLA/TCP/DBM: osteoinduction was observed around the DMB particles present at the outer part of the scaffolds and occured mainly on the dural side (Fig. 2B) resulting in an improved ossification along the dura when compared to the PLA/TCP scaffold alone (Table 2A). The new bone formed a network with only few interconnections with the implants themselves. This could have been due to the presence of fibrous tissue in between the newly formed bony structures and implants. As for the scaffold material alone, no ossification inside the pores of the structure could be detected (Table 2B).

PLA/TCP seeded with fetal cells: beside ossification along the dura confirming the osteoconductive properties of the scaffold material (Table 2A), new bone was also forming in the middle of the scaffold material filling its porous structure (Table 2B, Fig. 2C). However, the filling of pores did not correlate to the bone formation at the interface between the dura and the construct. Complete bridging of the defect with new bone was observed within this group. Mature mineralized bone with osteocytes were found in the porous structures and 
PLA/TCP

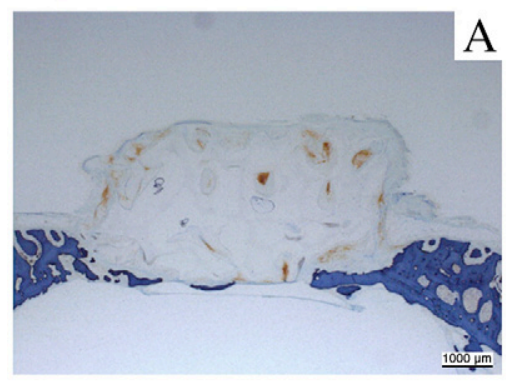

$\beta$ TCP Mathys

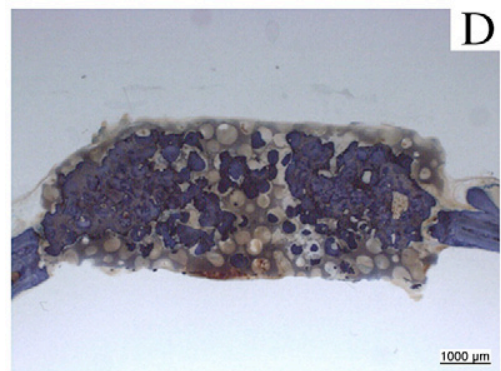

PLA/TCP/DBM

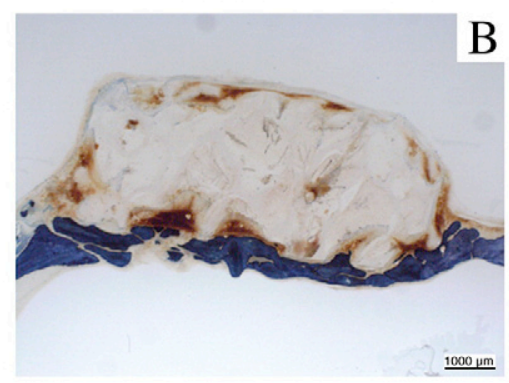

$\beta T C P$ Mathys/DBM

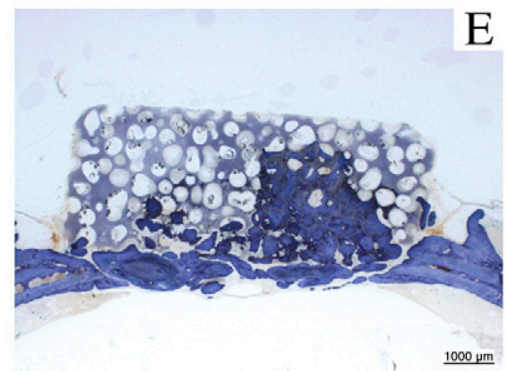

$\mathrm{PLA} / \mathrm{TCP}+$ fetal cells

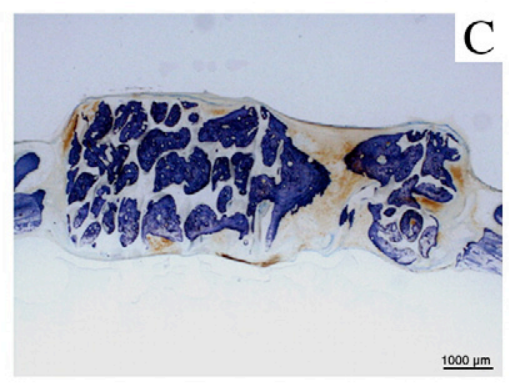

Sham

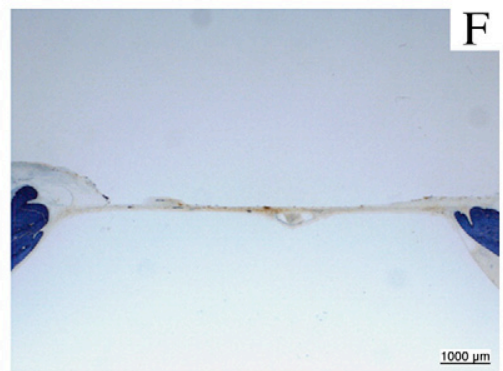

Fig. 2. Photomicrographs of histological sections of the cranial vaults 12 months after implantation. (A) PLA 5 wt.\% $\beta$-TCP, (B) PLA 5 wt.\% $\beta$-TCP/DBM, (C) PLA 5 wt.\% $\beta$-TCP with fetal bone cells, (D) $\beta$-TCP Mathys, (E) $\beta$-TCP Mathys/DBM, and (F) Sham operated group. Best repair images are shown. No healing was observed in the sham operated group. Samples were fixed in formaldehyde and processed for histological analysis. To visualize bone formation, frontal sections of $300 \mu \mathrm{m}$ thickness were ground down to $30-40 \mu \mathrm{m}$, polished, and stained with toluidine blue. Scale bar: $1 \mathrm{~mm}$.

front lines of osteoblasts were observed, directly on the osteoid (Fig. 3).

B-TCP Mathys: a good osteoconduction of the ceramic was observed, and the volume of the scaffolds were partly ossified, with numerous pores already filled with bone (Table 2B, Fig. 2D). In contrast to the PLA/TCP scaffolds, almost no ossification along the dura occured (Table 2A).

$\beta$-TCP Mathys/DBM: together with the osteoconduction inherent to scaffolds made of $\beta$-TCP (Table 2B, Fig. 2D), osteoinduction was observed around the DMB particles located on the dural side of the scaffolds (Table 2A, Fig. 2E). The new bone formed a grid infiltrating superficially the porous structures of the implants.

\section{Histology of femoral samples}

Indications of PLA/TCP scaffold resorption were apparent 2 months postoperatively. Changes were structural and concerned volume and porosity. Particular changes were more obvious when fetal cells were seeded on bone substitutes, and fragmentation was rarely observed. Bone healing assessed at this time point is illustrated by photomicrographs of stained femoral sections in Fig. 4.

PLA/TCP: implants were surrounded by new bone, formed either by prolongations of the cortical shell or by expansions of the metaphysiseal trabecular lattice, confirming the osteoconductivity of these structures observed in the skulls.
Infiltrations of newly synthesized bone were strong at the periphery of the scaffolds and remained reduced in the center (Fig. 4A and C).

PLA/TCP seeded with fetal bone cells: implants were also well anchored into the neighboring bone. Notable stronger infiltrations of new bone were assessed in the volume of the scaffolds when compared with PLA/TCP alone (Fig. 4B and D). The histomorphometrical analysis showed a statistically significant difference regarding the quantity of new bone formation within PLA/TCP implants loaded with fetal cells in comparisson with PLA/TCP implants alone $\left(+89 \% ; p=4 \times 10^{-6}\right)$.

\section{Radiography of rat specimen}

The presence of newly formed bone was confirmed radiographically in the cranial defects (Fig. 5). Whereas no new bone formation occurred in the sham control group, an increase in the area of radiopacity representing bone repair was observed within the skull defects between 12 days, 6 and 12 months for all PLA/TCP implants tested resulting in statistically significant differences over time. Furthermore, differences between PLA/ TCP and PLA/TCP + fetal bone cells were significant at 12 months $(+40 \% ; p=0.004)$. PLA/TCP/DBM scaffolds were significantly different from PLA/TCP structures starting from the first time point and this is thought to be due to the coating itself. Due to $\beta$-TCP Mathys cements high refringence to X-rays resulting in an intensity close to saturation, new bone formation 

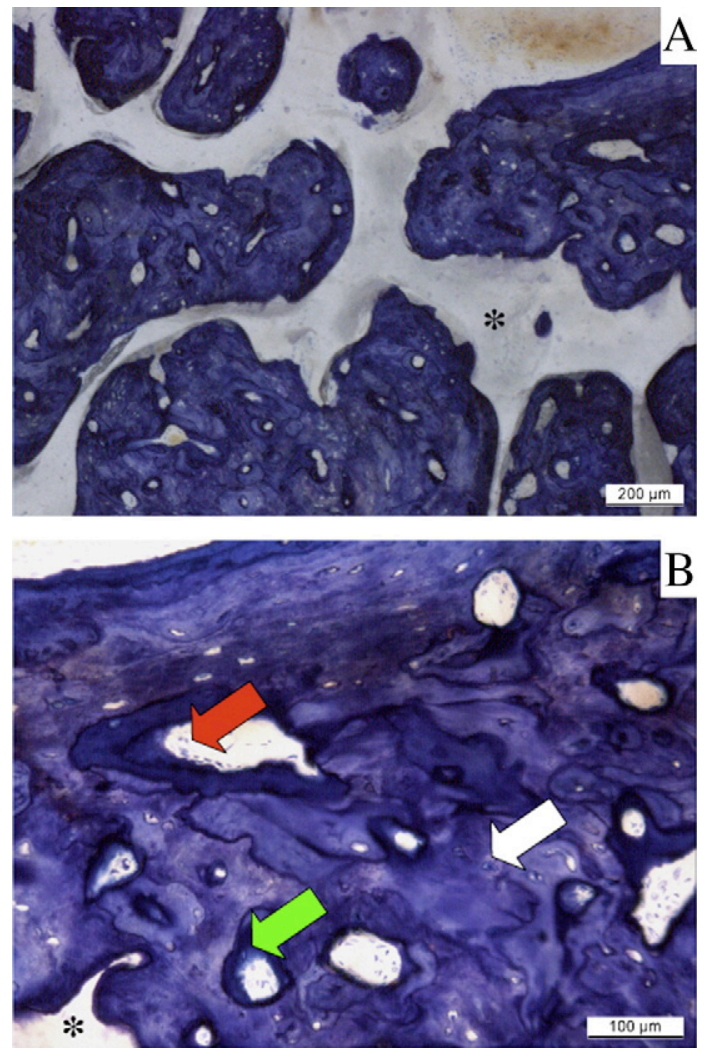

Fig. 3. Photomicrographs of histological sections of the cranial vaults 12 months after implantation of PLA 5 wt.\% $\beta$-TCP seeded with fetal bone cells. (A) Ossification of the scaffold and (B) details showing the process of bone formation within the pores. Metachromatically stained osteoid (green arrow) is deposited by a front of osteoblasts (red arrow), whereas mature bone with numerous osteocytes is seen in the vicinity (white arrow). Samples were formaldehyde fixed and processed for histological analysis. To visualize bone formation, frontal sections of $300 \mu \mathrm{m}$ thickness were ground down to 30-40 $\mu \mathrm{m}$, polished, and stained with toluidine blue. (*) Scaffold localization. Scale bars: (A) $200 \mu \mathrm{m}$ and (B) $100 \mu \mathrm{m}$.

could not be detected using this method for the $\beta$-TCP Mathys and $\beta$-TCP Mathys/DBM groups. Therefore, values obtained for these groups were not treated statistically.

Bone infiltration was also observed in the femoral implants, and seeding of the implants with human fetal bone cells did promote this phenomenon (Fig. 6).

\section{Discussion}

The aim of this study was to test the association of fetal bone cells with ceramic reinforced PLA scaffolds for tissue engineering. As animal models, the CSD craniotomy and the femoral condyle approaches in rats were chosen to follow cortical and trabecular bone repair processes. Key findings were the observation of complete bone bridging 12 months after implantation in skulls of PLA porous structures seeded with human fetal bone cells, and a strong induction of trabecular bone ingrowth in femoral condyles 2 months after surgery. As almost no new bone formation could be observed in the pores when implanting the scaffold material alone in the craniotomy model, the observed ossification can be assigned to the osteogenic potential of the fetal cells.

Firstly, we investigated PLA/ceramic resorption, as it is particularly important for bone implants that degradation does not occur before bone healing. Scaffold degradation is dependent on bone turnover and could be influenced by other factors, such as the access to vasculature, the mechanical loading, and the metabolism of degradation products [34]. Pure PLA scaffolds were shown to be degradable in rats [19] and in rabbits [35]. One advantage of combining ceramic and polymer is to control resorption rates [36]. In a pilot study in cranial defects in rats, the same PLA/ceramic scaffolds as used in this study did not show signs of alteration during the first 3 months after implantation (unpublished results), whereas fragmentation was observed after 18 weeks [6]. In the present work, and confirming these observations, changes in scaffold morphology were not noticed before 6 months post-surgery in the cranial model. The biological inertness of the skull compared with long bones is suggested to be due to a poor blood supply and a relative deficiency of bone marrow [12]. In the highly vascularized and mechanically stressed femoral condyle model, alterations of the implant structures were already observed at 2 months and were concomitant with bone remodelling. The presence of human fetal bone cells did enhance this process. Thus, PLA/TCP scaffolds obtained by critical gas foaming showed an interesting behaviour, as their degradation was associated with tissue repair.

Secondly, we characterized the ability of the structures to guide osteoprogenitor cells leading to new bone formation. Morphologically and embryologically, the calvaria develops from a membrane precursor and thus resembles the membranous bones of the face. Intramembranous ossification is characterized by the direct mineralization of a highly vascular connective tissue membrane. Trephine defects were shown to heal not only by ingrowth from the rim, but also by proliferation of perivascular mesenchymal-type cells of the dura mater [37]. In the first few days of bony repair, cells are migrating, attaching, and differentiating into osteoblasts to propagate bone growth [7]. It is known that porosity and pore size tend to affect osseointegration. Interconnected pores or open porosity is required for vascularization and nutrient diffusion. Thus, interconnection of the macropores plays a crucial role for cell migration and colonization of the inner scaffold. This parameter was not specifically evaluated in this work, and a partial interconnection could explain why, as in other studies [38,39], the new bone was mainly seen to be lining the osteoconductive walls of the composite matrix. Optimization of the foaming conditions to tailor foam parameters to trabecular bone properties are described elsewhere [3]. Foaming conditions were adjusted in order to get open porosity and $200-500 \mu \mathrm{m}$ pore diameters. Porosity and pore size can be adjusted playing with saturation pressure and temperature, depressurization rates and cooling rates. For example, high pressure will correspond to high $\mathrm{CO}_{2}$ concentration in the molten polymer and therefore a higher porosity. According to Boyan et al. 1996 [40], in the case of ceramic scaffolds, a macroporosity of $200-400 \mu \mathrm{m}$ is needed to promote bone cell attachment, and a large available surface area will favour cell attachment and spreading. However, in the case of the PLA/TCP 
PLA/TCP
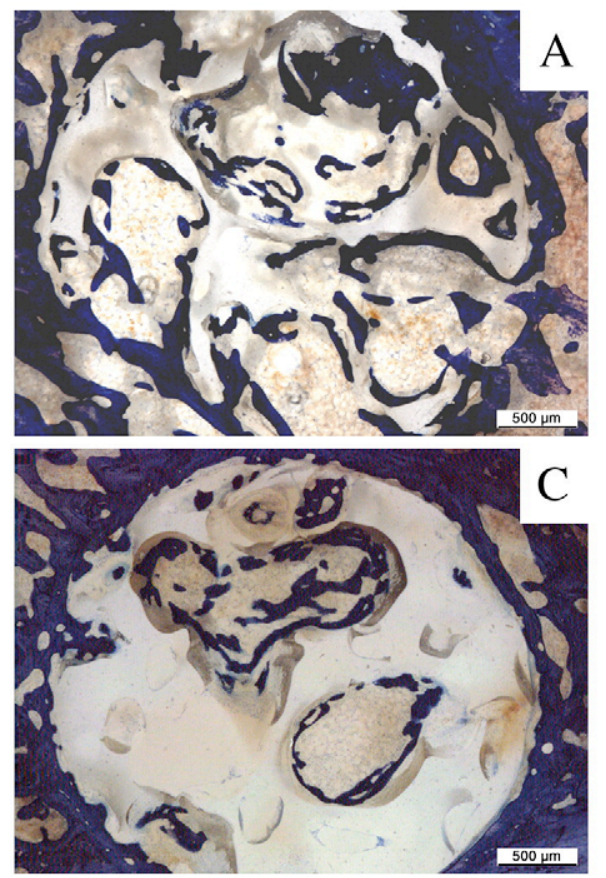

Implants
PLA/TCP + fetal cells
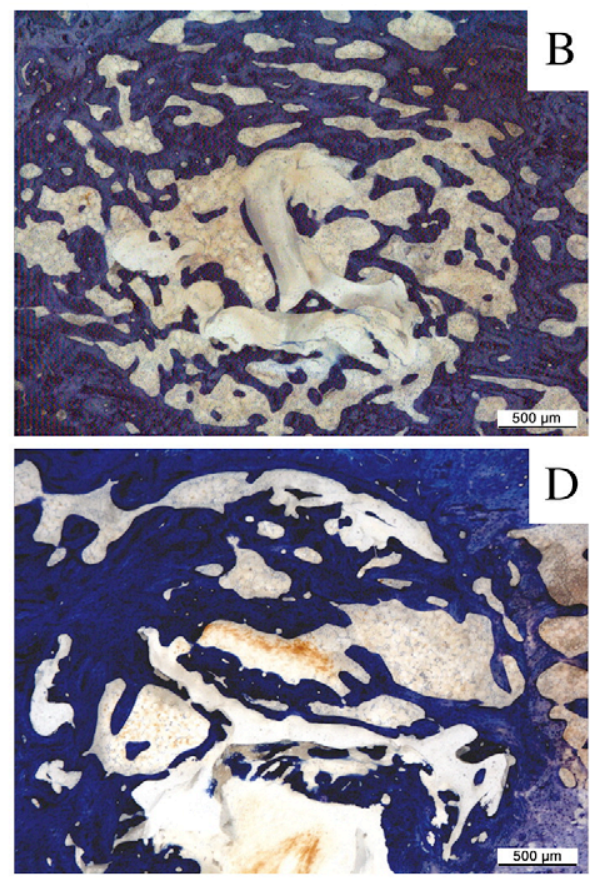

New Bone

(\% of total implant area)

PLA/TCP

$$
\text { PLA/TCP + fetal cells }
$$

$23.9( \pm 5.1)$

$45.1( \pm 10.7)$

Fig. 4. Histology and histomorphometrical analysis of femoral implants 2 months after implantation. Representative photomicrographs of histological femoral sections of different animals are shown. (A and C) PLA 5 wt.\% $\beta$-TCP alone and (B and D) PLA 5 wt.\% $\beta$-TCP seeded with fetal bone cells. Samples were fixed in formaldehyde and processed for histological analysis. To visualize bone formation, sagittal sections of $300 \mu \mathrm{m}$ thickness were ground down to $30-40 \mu \mathrm{m}$, polished and stained with toluidine blue. Scale bar: $500 \mu \mathrm{m}$. Histomorphometrical analysis of sections from PLA 5 wt. $\% \beta$-TCP alone and PLA 5 wt.\% $\beta$-TCP seeded with fetal bone cells was performed using one representative section per implant (12 implants per group). Thick sections were photographed and only the defect area corresponding to the implant itself was analyzed. New bone was stained manually to ensure accurate detection during the measurement. Absolute values were converted into percentages of the total area. Results are given as mean values with associated standard deviation of the mean. The difference between PLA 5 wt.\% $\beta$-TCP and PLA 5 wt. $\% \beta$-TCP + fetal bone cells was significant $\left(+89 \% ; p=4 \times 10^{-6}\right)$.

biocomposite, fetal bone cell development did not seem to be affected by differences in porosity and pore size in vitro [2]. In a preliminary in vivo study concerning PLA/TCP obtained by supercritical gas foaming, only one type of porous structure, porosity and pore size was tested and bone repair was assessed [6]. The aim of the present study was to evaluate the osteogenicity of fetal bone cells in vivo when associated to PLA/TCP scaffolds. Thus, structural parameters were kept identical to the preliminary study.

In contrast to this observation, the already clinically used $\beta$ TCP Mathys material showed enhanced osteoconduction resulting in ossification within the porous structures of the implants. Lytic zones resulting from polymer hydrolysis [41] or degradation-induced inflammation and bone resorption [42] were observed in canine models with scaffolds made of poly(L-lactic-co-glycolic acid) associated with BMP-2. In this study, although local bone degradation could have occurred, radiopacity of X-rays was increasing in a time-dependent fashion with all scaffold groups made of PLA indicating rather bone formation than resportion. This analytical method coupled to histology was suitable to follow bone formation in PLA/TCP scaffolds and to describe the precise location of the newly formed bone. Osteogenic properties of human fetal bone cells lead to bone formation within the scaffold volumes, whereas DBM coating did facilitate bone formation along the dura.

Moreover, the thin trabeculae of the metaphysis were found to progress around and into the implants, leading to improved implant integration and repair of the femoral defects. Best results were obtained when fetal bone cells were present in the scaffolds, and healing of the cranial and femoral defects with PLA/ceramic structures seeded with human fetal bone cells were observed by histology and confirmed by radiography. The 


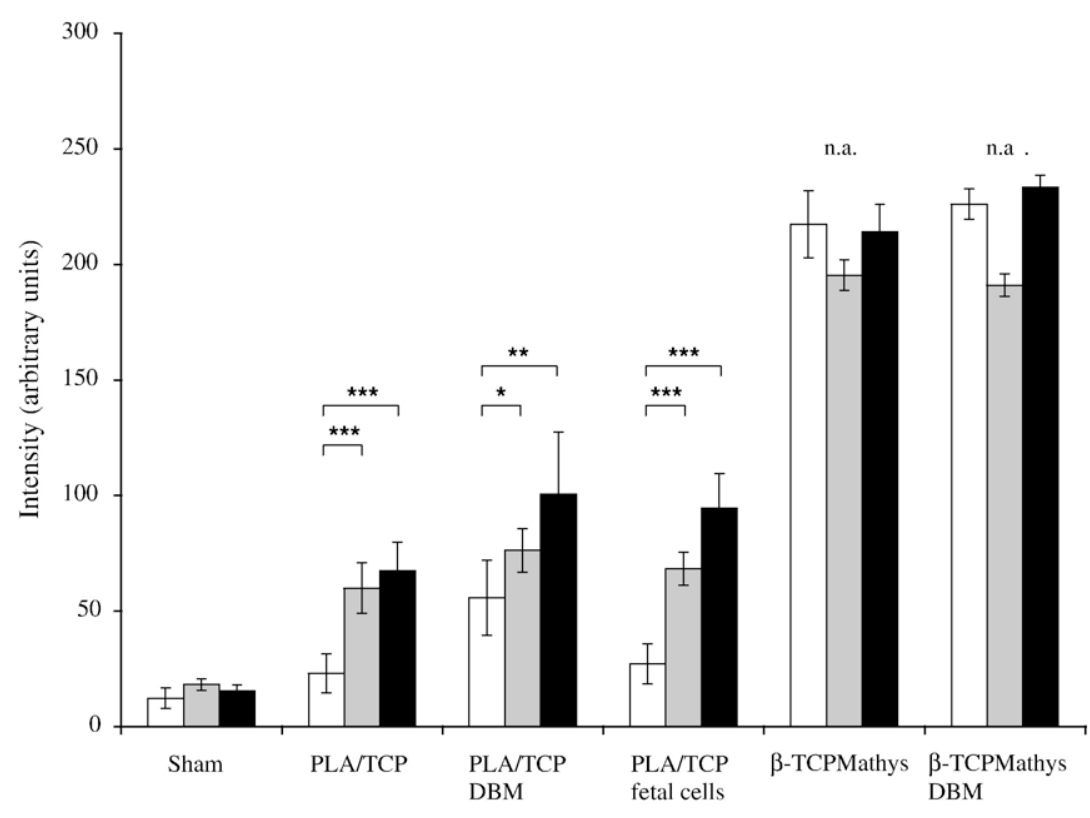

Fig. 5. Radiographic analysis of cranial trephine defects in adult rat skulls. The exocranial surfaces were exposed on top of a radiographic film. Samples were imaged and processed with an image analysis software. Histograms of each defect area were determined on digitized radiographs, and background values were subtracted. X-rays were taken 12 days, 6 months, and 12 months after the surgical intervention. Results are presented as mean values with associated standard deviation of the mean. Statistically significant differences over time within each group of implants are noted as follows: $(*)$ for $p<0.05 ;(* *)$ for $p<0.01$ and $(* * *)$ for $p<0.001$. Due to $\beta$-TCP Mathys cements high refringence to X-rays showing intensities close to saturation, new bone formation was not detectable in the $\beta$-TCP Mathys and $\beta$-TCP Mathys/DBM groups, and values obtained for these groups were not treated statistically (n.a.). No new bone formation occurred in the sham group.

osteogenic properties observed in xenogeneic implants might have been reduced due to adverse response of the hosts, as reported with MSCs from rats used in mice [43]. Although if immunoprivilege of fetal and adult MSCs is described [44], immune response in xenogeneic species cannot be excluded. However, as there was no immune response detectable after 12 months corresponding to a long-term follow-up in the rat, no later immune response is expected. Further studies must be undertaken to evaluate the respective actions of host and donor cells in the healing process observed. It might be possible that fetal bone cells initiate the process of bone repair which could be then continued by the host cells. A preliminary study showed that human cells were still detectable in cranial implants 4 weeks after surgery (unpublished results).

Based on these promising results, human fetal bone cells in combination with PLA/TCP scaffolds will be integrated in long bones defects in larger animals for further preclinical evaluation.

\section{Summary}

The in vivo behaviour of PLA/ceramic foams in combination with human fetal cells was assessed in terms of scaffold resorption as well as cortical and trabecular bone repair. The
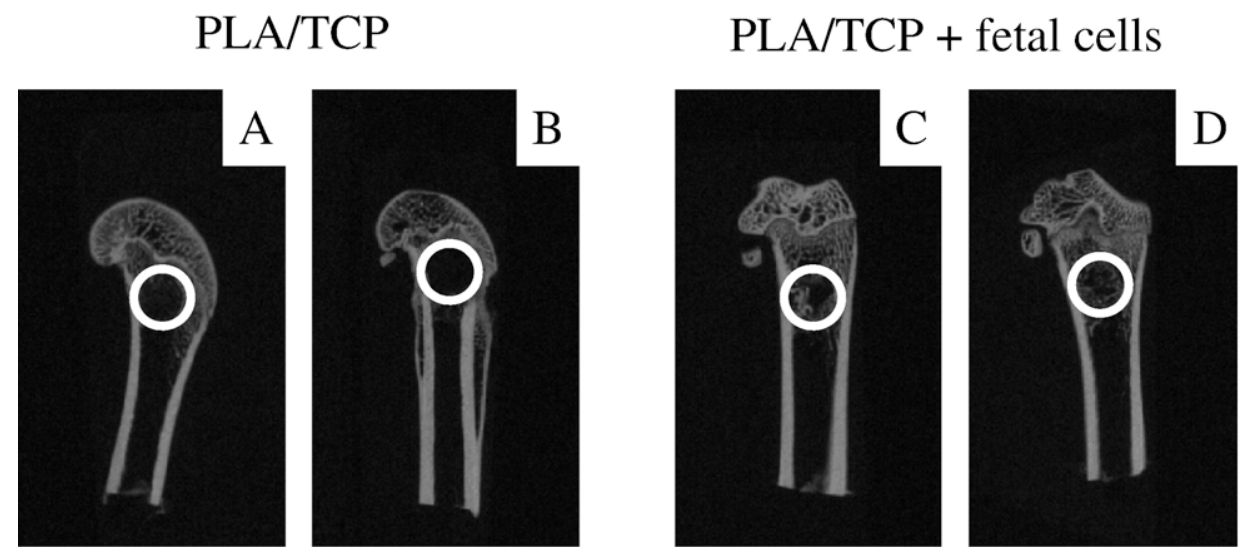

Fig. 6. Roentgenograms of femoral drill defects in rats 2 months after the surgical intervention. Femurs were radiographed as thick sections of $300 \mu \mathrm{m}$, in order to visualize bone infiltration in implants without surrounding bone. Representative images of PLA $5 \mathrm{wt} . \% \beta$-TCP implants without cells (A and B) and with human fetal bone cells $(\mathrm{C}$ and $\mathrm{D})$ are shown. Implantation sites are indicated with circles. 
degradation rate was coupled to the rate of tissue regeneration, leading to a structural integrity of the constructs. The presence of human fetal bone cells did improve the overall healing process when compared to the scaffold material alone. A complete reconstruction of the cranial vault was observed within the porous architecture of PLA/ceramic constructs seeded with human fetal cells. We conclude that PLA/ceramic architectures obtained by melt-extrusion coupled with supercritical gas foaming offer suitable conditions for host tissue integration and that the addition of human fetal cells can further improve their performance. This new approach to create composite structures and subsequently combine them with human fetal bone cells is promising for tissue engineering, especially for applications in maxillofacial bone repair and during revision of total joint replacement. In the perspective for use in tissue engineering, fetal bone cells could be selected regarding osteogenic and immune-related properties (unpublished results), along with their rapid growth, ease of cell banking and associated safety.

\section{Acknowledgments}

We thank PD Dr. Brigitte von Rechenberg, Katalin Zlinsky, Käthi Kämpf and Jens Langhoff from the Musculoskeletal Research Unit, Equine Clinic, University of Zürich, Switzerland, for scientific discussions, Veronique Garea from the Laboratory for Regenerative Medicine and Pharmacobiology (EPFL-LMRP), Ecole Polytechnique Fédérale de Lausanne, Switzerland, for assistance during surgery, Sandra Jaccoud from the Laboratory of Biomechanical Orthopedics (EPFL-HOSR), Ecole Polytechnique Fédérale de Lausanne, Switzerland, for excellent technical assistance, Dr. Andrea Tami from AO Foundation, Davos, Switzerland, for microtomographic analysis, the Interdisciplinary Center for Electron Microscopy (EPFL-CIME), Ecole Polytechnique Fédérale de Lausanne, Switzerland, for imaging, and Dr. R. Mathys Foundation, Bettlach, Switzerland, for the $\beta$-TCP scaffolds. This study was supported by grants from the Swiss National Science Foundation (FNRS No. 2100-066872.04.01), the Fondation Lémanique pour la Recherche sur le Tissu Osseux, and by the Lausanne Center for Bone Tissue Engineering.

\section{References}

[1] Montjovent MO, Burri N, Mark S, Federici E, Scaletta C, Zambelli PY, et al. Fetal bone cells for tissue engineering. Bone 2004;35(6):1323-33.

[2] Montjovent MO, Mathieu LM, Hinz B, Applegate LL, Bourban PE, Zambelli PY, et al. Biocompatibility of bioresorbable PLA composite scaffolds obtained by supercritical gas foaming with human fetal bone cells. Tissue Eng 2005;11(11/12):1640-9.

[3] Mathieu LM, Montjovent MO, Bourban PE, Pioletti DP, Månson JAE. Bioresorbable composites prepared by supercritical fluid foaming. J Biomed Mater Res A 2005;75(1):89-97.

[4] Hile DD, Amirpour ML, Akgerman A, Pishko MV. Active growth factor delivery from poly(D,L-lactide-co-glycolide) foams prepared in supercritical CO2. J Control Release 2000;66(2-3):177-85.

[5] Forman S, Kas J, Fini F, Steinberg M, Ruml T. The effect of different solvents on the ATP/ADP content and growth properties of HeLa cells. J Biochem Mol Toxicol 1999;13(1):11-5.
[6] Montjovent MO, Mathieu L, Schmoekel H, Mark S, Bourban PE, Zambelli PY, et al. Repair of critical size defects in the rat cranium using ceramicreinforced PLA scaffolds obtained by supercritical gas foaming. J Biomed Mater Res A 2007;83(1):41-51.

[7] Hollinger JO, Kleinschmidt JC. The critical size defect as an experimental model to test bone repair materials. J Craniofac Surg 1990;1(1):60-8.

[8] Schmitz JP, Hollinger JO. The critical size defect as an experimental model for craniomandibulofacial nonunions. Clin Orthop Relat Res 1986(205):299-308.

[9] Aalami OO, Nacamuli RP, Lenton KA, Cowan CM, Fang TD, Fong KD, et al. Applications of a mouse model of calvarial healing: differences in regenerative abilities of juveniles and adults. Plast Reconstr Surg 2004;114(3):713-20.

[10] Mulliken JB, Glowacki J. Induced osteogenesis for repair and construction in the craniofacial region. Plast Reconstr Surg 1980;65(5):553-60.

[11] Frame JW. A convenient animal model for testing bone substitute materials. J Oral Surg 1980;38(3):176-80.

[12] Prolo DJ, Pedrotti PW, Burres KP, Oklund S. Superior osteogenesis in transplanted allogeneic canine skull following chemical sterilization. Clin Orthop Relat Res 1982(168):230-42.

[13] Lindholm TC, Lindholm TS, Alitalo I, Urist MR. Bovine bone morphogenetic protein (bBMP) induced repair of skull trephine defects in sheep. Clin Orthop Relat Res 1988;227:265-8.

[14] Ripamonti U. Bone induction in nonhuman primates. An experimental study on the baboon. Clin Orthop Relat Res 1991(269):284-94.

[15] Dahlin C, Alberius P, Linde A. Osteopromotion for cranioplasty. An experimental study in rats using a membrane technique. J Neurosurg 1991;74(3):487-91

[16] Glowacki J, Altobelli D, Mulliken JB. Fate of mineralized and demineralized osseous implants in cranial defects. Calcif Tissue Int 1981;33(1):71-6.

[17] Turnbull RS, Freeman E. Use of wounds in the parietal bone of the rat for evaluating bone marrow for grafting into periodontal defects. J Periodontal Res 1974;9(1):39-43.

[18] Freeman E, Turnbull RS. The value of osseous coagulum as a graft material. J Periodontal Res 1973;8(4):229-36.

[19] Cutright DE, Perez B, Beasley III JD, Larson WJ, Posey WR. Degradation rates of polymers and copolymers of polylactic and polyglycolic acids. Oral Surg Oral Med Oral Pathol 1974;37(1):142-52.

[20] Vainionpaa S. Biodegradation of polyglycolic acid in bone tissue: an experimental study on rabbits. Arch Orthop Trauma Surg 1986;104 (6):333-8.

[21] Matsusue Y, Hanafusa S, Yamamuro T, Shikinami Y, Ikada Y. Tissue reaction of bioabsorbable ultra high strength poly (L-lactide) rod. A longterm study in rabbits. Clin Orthop Relat Res 1995(317):246-53.

[22] Kondo N, Ogose A, Tokunaga K, Ito T, Arai K, Kudo N, et al. Bone formation and resorption of highly purified beta-tricalcium phosphate in the rat femoral condyle. Biomaterials 2005;26(28):5600-8.

[23] Suganuma J, Alexander H. Biological response of intramedullary bone to poly-L-lactic acid. J Appl Biomater 1993;4:13-27.

[24] An YH, Woolf SK, Friedman RJ. Pre-clinical in vivo evaluation of orthopaedic bioabsorbable devices. Biomaterials 2000;21(24):2635-52.

[25] Connolly JF. Injectable bone marrow preparations to stimulate osteogenic repair. Clin Orthop Relat Res 1995(313):8-18.

[26] Quarto R, Mastrogiacomo M, Cancedda R, Kutepov SM, Mukhachev V, Lavroukov A, et al. Repair of large bone defects with the use of autologous bone marrow stromal cells. N Engl J Med 2001;344(5):385-6.

[27] Krebsbach PH, Mankani MH, Satomura K, Kuznetsov SA, Robey PG. Repair of craniotomy defects using bone marrow stromal cells. Transplantation 1998;66(10):1272-8.

[28] Winn SR, Randolph G, Uludag H, Wong SC, Hair GA, Hollinger JO. Establishing an immortalized human osteoprecursor cell line: OPC1. J Bone Miner Res 1999;14(10):1721-33.

[29] Mathieu L, Bourban PE, Månson JAE. Processing of homogeneous ceramic/polymer blends for bioresorbable composites. Composites Science and Technology 2006;66:1606-14.

[30] Mathieu LM, Mueller TL, Bourban PE, Pioletti DP, Muller R, Månson JAE. Architecture and properties of anisotropic polymer composite scaffolds for bone tissue engineering. Biomaterials 2006;27(6):905-16. 
[31] Lieberman JR, Le LQ, Wu L, Finerman GA, Berk A, Witte ON, et al. Regional gene therapy with a BMP-2-producing murine stromal cell line induces heterotopic and othotopic bone formation in rodents. J Orthop Res 1998;16(3):330-9.

[32] Bruder SP, Kraus KH, Goldberg VM, Kadiyala S. The effect of implants loaded with autologous mesenchymal stem cells on the healing of canine segmental bone defects. J Bone Jt Surg Am 1998;80(7):985-96.

[33] Theiss F, Apelt D, Brand B, Kutter A, Zlinszky K, Bohner M, et al. Biocompatibility and resorption of a brushite calcium phosphate cement. Biomaterials 2005;26(21):4383-94.

[34] Temenoff JS, Mikos AG. Injectable biodegradable materials for orthopedic tissue engineering. Biomaterials 2000;21(23):2405-12.

[35] Matsusue Y, Yamamuro T, Oka M, Shikinami Y, Hyon SH, Ikada Y. In vitro and in vivo studies on bioabsorbable ultra-high-strength poly(L-lactide) rods. J Biomed Mater Res 1992;26(12):1553-67.

[36] Wang M. Developing bioactive composite materials for tissue replacement. Biomaterials 2003;24(13):2133-51.

[37] Takagi K, Urist MR. The reaction of the dura to bone morphogenetic protein (BMP) in repair of skull defects. Ann Surg 1982;196(1):100-9.

[38] Kadiyala S, Young RG, Thiede MA, Bruder SP. Culture expanded canine mesenchymal stem cells possess osteochondrogenic potential in vivo and in vitro. Cell Transplant 1997;6(2):125-34.

[39] Ishaug-Riley SL, Crane GM, Gurlek A, Miller MJ, Yasko AW, Yaszemski MJ, et al. Ectopic bone formation by marrow stromal osteoblast transplantation using poly(DL-lactic-co-glycolic acid) foams implanted into the rat mesentery. J Biomed Mater Res 1997;36(1):1-8.

[40] Boyan BD, Hummert TW, Dean DD, Schwartz Z. Role of material surfaces in regulating bone and cartilage cell response. Biomaterials 1996;17(2):137-46.

[41] Fischgrund JS, James SB, Chabot MC, Hankin R, Herkowitz HN, Wozney $\mathrm{JM}$, et al. Augmentation of autograft using rhBMP-2 and different carrier media in the canine spinal fusion model. J Spinal Disord 1997;10(6):467-72.

[42] David SM, Gruber HE, Meyer Jr RA, Murakami T, Tabor OB, Howard BA, et al. Lumbar spinal fusion using recombinant human bone morphogenetic protein in the canine. A comparison of three dosages and two carriers. Spine 1999;24(19):1973-9.

[43] Wang Y, Chen X, Armstrong MA, Li G. Survival of bone marrow-derived mesenchymal stem cells in a xenotransplantation model. J Orthop Res 2007.

[44] Le Blanc K, Tammik C, Rosendahl K, Zetterberg E, Ringden O. HLA expression and immunologic properties of differentiated and undifferentiated mesenchymal stem cells. Exp Hematol 2003;31(10):890-6. 